RICCIARDI SBIZERA, José Alexandre. Direito e literatura: (des)caminhos possíveis para um ensino jurídico crítico. Revista Eletrônica Direito e Política, Programa de Pós-Graduação Stricto Sensu em Ciência Jurídica da UNIVALI, Itajaí, v.16, n.1, $1^{0}$ quadrimestre de 2021. Disponível em: www.univali.br/direitoepolitica - ISSN 1980-7791

\title{
DIREITO E LITERATURA: (DES)CAMINHOS POSSÍVEIS PARA UM ENSINO JURÍDICO CRÍTICO
}

\author{
LAW AND LITERATURE: POSSIBLE (DIS) WAYS FOR CRITICAL LEGAL \\ EDUCATION
}

José Alexandre Ricciardi Sbizera ${ }^{1}$

\begin{abstract}
RESUMO
O presente artigo tem como objetivo aproximar Direito e Literatura para um ensino jurídico crítico. Para isso, faz-se um panorama sobre o ensino jurídico tradicional; demonstra-se de maneira breve as abordagens possíveis entre Direito e Literatura; expõe-se as duas aproximações com maior capacidade de auxílio pedagógico e, a partir daí, traça-se os caminhos destas abordagens que possibilitam um ensino jurídico diferente. Ao final, espera-se entender que o uso da literatura é modo alternativo privilegiado no sentido de auxiliar e guiar o ensino e a aprendizagem do direito, bem como despertar a curiosidade para seu efetivo uso.
\end{abstract}

PALAVRAS-CHAVE: Direito e Literatura; Ensino Jurídico; Pensamento Jurídico Crítico.

\begin{abstract}
This article aims to bring Law and Literature closer to a critical legal education. For this, an overview of traditional legal education is made; the possible approaches between Law and Literature are briefly demonstrated; the two approaches with the greatest capacity for pedagogical assistance are exposed and, from there, the paths of these approaches are outlined that enable a different legal teaching. In the end, we hope to understand that the use of literature is a privileged alternative in the sense of assisting and guiding the teaching and learning of law, as well as arousing curiosity for its effective use.
\end{abstract}

KEY-WORDS: Law and Literature; Legal Education; Critical Legal Thinking

\footnotetext{
${ }^{1}$ Doutor e Mestre em Direito pela Universidade Federal de Santa Catarina (UFSC); Especialista em Direito e Processo Penal pela Universidade Estadual de Londrina (UEL); Bacharel em Direito pela Universidade do Norte do Paraná (UNOPAR). Professor da Escola de Direito das Faculdades Londrina, do curso de Direito da Universidade Positivo em Londrina e do curso de Direito das Faculdades Integradas do Vale do Ivaí. Londrina, Paraná. E-mail para contato: jarsbizera@gmail.com
} 
RICCIARDI SBIZERA, José Alexandre. Direito e literatura: (des)caminhos possíveis para um ensino jurídico crítico. Revista Eletrônica Direito e Política, Programa de Pós-Graduação Stricto Sensu em Ciência Jurídica da UNIVALI, Itajaí, v.16, n.1, $1^{0}$ quadrimestre de 2021. Disponível em: www.univali.br/direitoepolitica - ISSN 1980-7791

\section{INTRODUÇÃo}

Final da segunda década do século XXI; mais de cento e noventa anos já se passaram desde a criação dos primeiros cursos de Direito no Brasil; aumentam o número de faculdades de Direito em todo o país; e a conduta tradicional em sala de aula continua sendo a mesma.

Aquele caráter conservador herdado da Universidade de Coimbra trazido pelos primeiros bacharéis aqui formados, ao que parece, continua em voga ${ }^{2}$. As monótonas, repetitivas, reprodutoras, conservadoras, alheias e isoladas escolas de direito continuam repassando conteúdos formais em detrimentos de atitudes, condutas e habilidades críticas; constata-se a falta de ética, a desatenção às mudanças no mundo, a desvinculação com as comunidades vizinhas, a simulação da prática, e o ensino jurídico como gerador do que Roberto de Aguiar chama de "velhice precoce"3.

Admira-se a opulência das cátedras universitárias; as belíssimas bibliotecas; o fino terno engomado; as grandes cabeças untadas de gel; as relações formais e almofadadas; o vocabulário pomposo, sofisticado e ritualizado; o ornamento, a retórica e o efeito ${ }^{4}$. Não se percebe o discurso vazio; o vocabulário técnico vazio; as relações vazias; as cabeças vazias; os ternos vazios; as bibliotecas vazias e as universidades vazias. Talvez nem tudo isto fisicamente, literalmente, mas de algum modo, certamente, vazios. Vazios, estéreis, inférteis na solução dos problemas reais.

Ocorre o que o jusfilósofo italiano Paolo Grossi chama de a perda da "dimensão sapiencial" do Direito 5 . E isto pode ter ocorrido, entre outros fatores, em razão do rápido aumento da quantidade de cursos de Direito no país nos últimos anos; da precária fiscalização destes cursos por parte dos órgãos responsáveis; da débil e insuficiente formação e capacitação teórica, pedagógica e educacional dos

\footnotetext{
2 Cf. ADORNO, Sérgio. Os aprendizes do poder: o bacharelismo liberal na política brasileira. Rio de Janeiro: Paz e Terra, 1988.

3 Cf. AGUIAR, Roberto A. R. de. Habilidades: ensino jurídico e contemporaneidade. Rio de Janeiro: DP\&A, 2004. p. 179 e ss.

${ }_{4}^{4}$ FONSECA, Ricardo Marcelo. Introdução teórica à história do direito. Curitiba: Juruá, 2009. p. 18.

5 Cf. GROSSI, Paolo. Mitologias jurídicas da modernidade. 2. ed. Florianópolis: Fundação Boiteaux, 2007. P. 15.
} 
RICCIARDI SBIZERA, José Alexandre. Direito e literatura: (des)caminhos possíveis para um ensino jurídico crítico. Revista Eletrônica Direito e Política, Programa de Pós-Graduação Stricto Sensu em Ciência Jurídica da UNIVALI, Itajaí, v.16, n.1, $1^{0}$ quadrimestre de 2021. Disponível em: www.univali.br/direitoepolitica - ISSN 1980-7791

docentes e, inclusive, da resistência a esta capacitação; do amadorismo pedagógico; da hipervalorização da prática e da experiência profissional fora da universidade e da hipovalorização da teoria; da constante e urgente necessidade de profissionais requisitados pelo mercado de trabalho; entre outras questões ${ }^{6}$.

Desta forma, as faculdades repassam para os acadêmicos um conhecimento para exames e concursos, de forma estanque, superficial, desconexa, fragmentada, es-que-ma-ti-zada, que, ao fim e ao cabo, só serve mesmo para o uso técnicoburocrático dos guichês, gabinetes e câmaras refrigeradas forenses.

Teorias jurídicas raramente são apresentadas com suas densidades e complexidades por professores e muito mais raramente apreendidas e honradas com o interesse dos acadêmicos. Os estudos do Direito são feitos à base da leitura de leis, sinopses, resumos e manuais, para não falar do famoso "plasticão jurídico"; e os vade-mecuns sãos as armas mais rapidamente sacadas frente a qualquer questionamento, verdadeiro oráculo do (des)conhecimento jurídico. Para Pedro Demo, um curso que tão somente prepara instrumentos humanos capazes de exercer profissões, mas dispensados da capacidade de questionamento sistemático promove, no fundo, "idiotas especializados em executar"7.

Durante o curso, as disciplinas de teor introdutório, pejorativamente denominados de propedêutico, tais como a filosofia, a sociologia, a economia, a psicologia, a ciência política e a história mais parecem um tipo de conhecimento jurídico clandestino, proibido. Ganham contornos monstruosos e são relegados a guetos, delineados por um pensamento preconceituoso, seco e grosseiro de que estas matérias não possuem utilidade e jamais serão usados em sua vida profissional. Diz-se comumente que "na prática a teoria é outra".

6 Cf. COLAÇO, Thais Luzia. Ensino do direito e capacitação docente. In. COLAÇO, Thais Luzia. (Org.). Aprendendo a ensinar direito o direito. Florianópolis: OAB/SC, 2006; BAZZO, Vera Lúcia. Algumas reflexões sobre a profissionalidade docente no contexto das políticas para a educação superior. In. COLAÇO, Thais Luzia. (Org.). Aprendendo a ensinar direito o direito. Florianópolis: $\mathrm{OAB} / \mathrm{SC}, 2006$.

7 Cf. DEMO, Pedro. Pesquisa e construção do conhecimento: metodologia científica no caminho de Habermas. 7. ed. Rio de Janeiro: Tempo Brasileiro, 2009. p. 29. 
RICCIARDI SBIZERA, José Alexandre. Direito e literatura: (des)caminhos possíveis para um ensino jurídico crítico. Revista Eletrônica Direito e Política, Programa de Pós-Graduação Stricto Sensu em Ciência Jurídica da UNIVALI, Itajaí, v.16, n.1, $1^{0}$ quadrimestre de 2021. Disponível em: www.univali.br/direitoepolitica - ISSN 1980-7791

Em sala de aula, predominam as práticas que Paulo Freire chama de "educação bancária", em que os professores seriam os que educam, que sabem, que pensam, que dizem, que disciplinam, que escolhem e prescrevem, que atuam, que programam, são os sujeitos do processo de conhecimento; enquanto que os alunos seriam os educados, os que não sabem, que não pensam ou são pensados, que escutam docilmente mas não são ouvidos, os disciplinados, que acatam e seguem a ordem e a prescrição, que se iludem na atuação do professor, são objetos do processo de conhecimento ${ }^{8}$. Esquece-se das exigências elencadas por ele em sua Pedagogia da Autonomia 9 .

Vygotsky, por sua vez, diria que a prática, que o desenvolvimento humano e as implicações educacionais que temos nas salas de aula dos cursos de Direito no Brasil seriam ambientalistas. Nesta perspectiva as práticas e conteúdos didáticos prescindem de relação com o cotidiano do aluno bem como das realidades sociais. Imperam a palavra do professor, a quem compete com exclusividade ensinar, avaliar, corrigir e julgar comportamentos e a produção do aluno, o qual deve apenas executar conforme Ihe foi mandado ${ }^{10}$.

Neste ambiente em que o professor é também advogado, juiz ou promotor qualquer coisa é aula; e nestas aulas, segundo Pedro Demo, ensinar é copiar. ${ }^{11}$ Não se aprende a aprender e a saber pensar para intervenção no mundo de modo inovador ${ }^{12}$. Como conseqüência disso as avaliações se tornam mera verificação de domínio de conteúdo, memorização mecânica, muitas vezes até uma punição, em detrimento de um saber pensar, de uma habilidade de argumentar e questionar ${ }^{13}$.

É neste contexto e contra esta série de problemas que se insere os estudos do Direito e Literatura. Pouco imaginado e aceito entre os juristas há cerca de vinte

\footnotetext{
${ }^{8}$ Cf. FREIRE, Paulo. Pedagogia do oprimido. Rio de Janeiro: Paz e Terra, 2005. p. 68.

9 Cf. FREIRE, Paulo. Pedagogia da autonomia: sabers necessários à prática educativa. 40. ed. São Paulo: Paz e Terra, 1996.

10 Cf. REGO, Teresa Cristina. Vygotsky: uma perspective histórico-cultural da educação. 20. ed. Petrópolis: Vozes, 2009. p. 89-90.

${ }^{11}$ Cf. DEMO, Pedro. Pesquisa e construção do conhecimento. p. 87.

12 Cf. DEMO, Pedro. Pesquisa e construção do conhecimento. p. 9.

13 Cf. DEMO, Pedro. Mitologias da avaliação: de como ignorar, em vez de enfrentar problemas.

2. ed. Campinas: Autores Associados, 2002. p. 41.
} 
RICCIARDI SBIZERA, José Alexandre. Direito e literatura: (des)caminhos possíveis para um ensino jurídico crítico. Revista Eletrônica Direito e Política, Programa de Pós-Graduação Stricto Sensu em Ciência Jurídica da UNIVALI, Itajaí, v.16, n.1, $1^{0}$ quadrimestre de 2021. Disponível em: www.univali.br/direitoepolitica - ISSN 1980-7791

anos, hoje se demonstram férteis os estudos que relacionam Direito e Literatura, que se proliferam por todo o Brasil, sendo este artigo mais um dentre eles.

Direito e Literatura possuem suas semelhanças, dentre as quais se podem destacar três principais: a linguagem (muito embora cada uma tenha suas especificidades ${ }^{14}$ ), suas relações entre os sujeitos (indivíduos, sociedades, leitores, personagens, autores, obras, etc.), e o destinatário (o humano). O ser humano é o centro da articulação entre o Direito e a Literatura.

São, no entanto, muito diferentes: o primeiro codifica a realidade, a segunda rechaça convenções; o primeiro estabiliza expectativas, a segunda provoca a emoção; o primeiro se refere ao comando e à ordem, a segunda pertence ao lúdico e ao fantasioso; o Direito estabelece sujeitos de direitos; a Literatura inventa personagens de todas as sortes; para citar só algumas das diferenças ${ }^{15}$. Mas é exatamente na constatação destas diferenças que se faz rica a aproximação entre Direito e Literatura. Trata-se de realizar abordagens inter e transdisciplinares, tal qual fala Edgar Morin ${ }^{16}$, na tentativa de fazer surgir, a partir daí, novos conhecimentos possíveis para alterações na realidade.

Faz-se o que na física, na geometria e na astronomia se chama de paralaxe, ou seja, uma mudança aparente do objeto contra um fundo devido ao movimento do observador; um deslocamento aparente da linha de visão; um descondicionamento do olhar. Observa-se, portanto, o jurídico a partir de fora, a partir da literatura.

Portanto, para os objetivos do presente artigo se fará, num primeiro momento, uma apresentação das abordagens possíveis entre Direito e Literatura; posteriormente se será problematizado qual destas abordagens

\footnotetext{
14 Cf. SBIZERA, José Alexandre Ricciardi; TRINDADE, André. Era uma vez o direito: a linguagem jurídico-artística. In. TRINDADE, André; SCHWARTZ, Germano. (Org.). Direito e literatura: o encontro entre Themis e Apolo. Curitiba: Juruá, 2008. p. 95 e ss.

${ }^{15}$ Cf. TRINDADE, André Karam; GUBERT, Roberta Magalhães. Direito e literatura: aproximações e perspectivas para se repensar o direito. In. TRINDADE, André Karam; GUBERT, Roberta Magalhães; COPETTI NETO, Alfredo. (Org.). Direito \& literatura: reflexões teóricas. Porto Alegre: Livraria do Advogado, 2008. p. 22-23; CUNHA, Paulo Ferreira da. Prefácio. In. TRINDADE; SCHWARTZ, 2008. p. 8.

16 MORIN, Edgar. A cabeça bem-feita: repensar a reforma, reformar o pensamento. 16. ed. Rio de Janeiro: Bertrand Brasil, 2009. p. 105 e ss.
} 
RICCIARDI SBIZERA, José Alexandre. Direito e literatura: (des)caminhos possíveis para um ensino jurídico crítico. Revista Eletrônica Direito e Política, Programa de Pós-Graduação Stricto Sensu em Ciência Jurídica da UNIVALI, Itajaí, v.16, n.1, $1^{0}$ quadrimestre de 2021. Disponível em: www.univali.br/direitoepolitica - ISSN 1980-7791

possíveis são as que melhor podem auxiliar e nortear o ensino e o aprendizado do Direito; ilustrando-se com alguns exemplos de excertos literários que são capazes de realizar tal intento. Passa-se, a seguir, ao estudo das abordagens entre Direito e Literatura.

\section{DIREITO E LITERATURA: ABORDAGENS POSSÍVEIS}

Desde o "estágio inaugural ${ }^{17 "}$ dos estudos feitos pelos "pais fundadores ${ }^{18 "}$ do Direito e Literatura nos Estados Unidos e na Europa há mais de cem anos, muitas abordagens e aproximações foram realizadas até que se iniciasse o chamado Movimento do Direito e Literatura ${ }^{19}$.

Antes dividido por grande parte dos pesquisadores, dentre os quais o mais conhecido é François Ost ${ }^{20}$, em três frentes de estudo, qual seja, o Direito na Literatura, o Direito como Literatura e o Direito da Literatura; hoje estas frentes são subdivididas, de modo a melhor especificar as abordagens e atuações de cada tipo de estudo, em seis. Estas subdivisões, sugeridas por Arnaldo Sampaio de Moraes Godoy, serão a referência utilizada no presente trabalho, e são as seguintes: a) o Direito na Literatura;b) a Literatura no Direito; c) a Literatura como possibilidade de expressão do Direito; d) o Direito, a Literatura, a narrativa e as possibilidades retóricas; e) o Direito a Literatura e a hermenêutica; f) o Direito, a Literatura e a questão da criptomnésia e o plágio ${ }^{21}$. Segue-se as considerações e detalhamentos sobre cada uma delas.

A versão do direito na literatura suscita dois olhares. De acordo com Godoy, o primeiro identificaria o jurista vasculhando na literatura exemplos e frases de

\footnotetext{
17 Cf. TRINDADE; GUBERT. In. TRINDADE; GUBERT; COPETTI NETO. Direto \& literatura: reflexões teóricas. p. 24-25.

18 Cf. GODOY, Arnaldo Sampaio de Moraes. Direito e literatura: os pais fundadores: John Henry Wigmore, Benjamin Nathan Cardozo e Lon Fuller. In. TRINDADE; SCHWARTZ, 2008. p. 21 e ss.; In. GONZÁLEZ, José Calvo. (Org.). Implicación derecho literatura: contribuciones a una teoría literaria del derecho. Granada: Editorial Comares, 2008. p. 41 e ss.

${ }^{19}$ Cf. TRINDADE; GUBERT. In. TRINDADE; GUBERT; COPETTI NETO, 2008. p. 25-48.

20 OST, François. Contar a lei : as fontes do imaginário jurídico. São Leopoldo: Unisinos, 2004.

${ }^{21}$ Cf. GODOY, Arnaldo Sampaio de Moraes. Direito \& literatura: ensaio de síntese teórica. Porto Alegre: Livraria do Advogado, 2008.
} 
RICCIARDI SBIZERA, José Alexandre. Direito e literatura: (des)caminhos possíveis para um ensino jurídico crítico. Revista Eletrônica Direito e Política, Programa de Pós-Graduação Stricto Sensu em Ciência Jurídica da UNIVALI, Itajaí, v.16, n.1, $1^{0}$ quadrimestre de 2021. Disponível em: www.univali.br/direitoepolitica - ISSN 1980-7791

efeito retórico para demonstrar cultura exacerbada, típica figura do bacharel que simula conhecimento 22 ; e o segundo que, entre outras coisas, ridiculariza justamente este primeiro. Como este é um dos modos a ser visto no próximo tópico basta, por ora, estas considerações. Cabe salientar, entretanto, que esta segunda busca do direito na literatura, que investiga a presença do jurídico nos textos literários é, por um lado, mais interessante que as aproximações seguintes. Isto porque as próximas abordagens são, em geral, impregnadas de critérios e dotadas de uma seriedade, de uma sisudez, que o próprio Direito e Literatura critica, que o próprio Direito e Literatura pretende refutar.

A segunda abordagem, o estudo da literatura no direito, focaliza aspectos discursivos na fala jurídica. Dá-se ênfase aos ruídos, aos problemas lingüísticos e a abordagem torna-se prisioneira da articulação entre emissor, receptor e mensagem. Procura-se o literário no jurídico; faz-se teoria e crítica literária nos textos jurídicos: decisões judiciais, petições, doutrinas e normas. ${ }^{23}$

A literatura como possibilidade de expressão do direito, por sua vez, sugere uso pedagógico da literatura. Usa-se intencionalmente um texto ficcional para transmitir conteúdo jurídico com objetivo de ensino. Por se tratar de um dos modos que será visto mais adiante, pouco se falará dele aqui, razão pela qual se segue com a próxima abordagem.

No caso do direito, literatura, narrativa e possibilidades retóricas o jurídico tornase espetáculo. Aqui o Direito se transforma em performance, explicação, fragmento de história. A literatura nesta abordagem é entendida em sentido amplo, podendo transformar o Direito em novela de televisão, em seriados, em programas de auditório, em que todos palpitam sobre as mais diversas temáticas jurídicas. ${ }^{24}$ Ressalte-se que isso não quer dizer que se despreza sabedoria popular que a arrogância da ciência relegou a senso comum como Paul Feyerabend já alertou em alguns textos. ${ }^{25}$

22 Cf. GODOY, Arnaldo Sampaio de Moraes. Direito \& literatura: ensaio de síntese teórica. p. 10. 23 Cf. GODOY, Arnaldo Sampaio de Moraes. Direito \& literatura: ensaio de síntese teórica. p. 12.

24 Cf. GODOY, Arnaldo Sampaio de Moraes. Direito \& literatura: ensaio de síntese teórica. p. 81.

25 FEYERABAND, Paul. Contra o método. São Paulo: UNESP, 2007. p. 17; Adeus à razão. São Paulo: UNESP, 2010. 
RICCIARDI SBIZERA, José Alexandre. Direito e literatura: (des)caminhos possíveis para um ensino jurídico crítico. Revista Eletrônica Direito e Política, Programa de Pós-Graduação Stricto Sensu em Ciência Jurídica da UNIVALI, Itajaí, v.16, n.1, 10 quadrimestre de 2021. Disponível em: www.univali.br/direitoepolitica - ISSN 1980-7791

Outro viés desta abordagem é o que se dedica a aspectos da construção da narrativa. Atenta-se para a forma, que não é formalismo, com a qual as idéias, conteúdos, são lançados para o leitor ou o ouvinte. Trata-se de convencer pelo melhor discurso. Se o direito coage, a literatura, a princípio, não. Com isso se busca, aqui, a coação mediante o caráter de icoagibilidade da literatura. A literatura, assim, alavanca o direito; e pode ser até mesmo usada como veículo para a revolução. Neste sentido, julgar seria optar por uma narrativa ou outra, criando uma outra narrativa, a sentença, que mais tarde virá a ser outra narrativa em um acórdão ou jurisprudência. ${ }^{26}$

No direito, literatura e hermenêutica tem-se a prática jurídica como exercício de interpretação e a justiça como tradução. No primeiro caso, na prática jurídica como exercício de interpretação, o maior expoente é Ronald Dworkin, que explora conexões indiretas entre teorias estéticas e políticas. Dworkin diz que não há uma interpretação única; que um romance pode ser lido de várias formas, assim como o direito; e o interprete faz estas leituras sempre baseado no conjunto de entendimentos que reflete tal ou qual linha ou escola de interpretação. Neste sentido a função do magistrado é a interpretação de uma história normativa contada, e não a criação de uma nova história, como no item anterior. ${ }^{27}$

O segundo caso, do entendimento da justiça como tradução, o estudioso mais profícuo é James White. Para ele, o exercício da tradução não é mera operação mecânica de apropriação de determinado material para recompô-lo em sua natureza textual. Tradução seria relação entre seres humanos, em que respondemos aos textos que lemos com nossos próprios textos que preparamos a partir da leitura de tantos outros textos. Com isso, nos faz pensar sobre o problema de se mal traduzir um texto ou uma realidade, nos alertando para o que chama de "ética do tradutor"28.

\footnotetext{
${ }^{26}$ Cf. GODOY, Arnaldo Sampaio de Moraes. Direito \& literatura: ensaio de síntese teórica p. 84. 27 Cf. GODOY, Arnaldo Sampaio de Moraes. Direito \& literatura: ensaio de síntese teórica p. 93 e SS.

${ }^{28}$ Cf. GODOY, Arnaldo Sampaio de Moraes. Direito \& literatura: ensaio de síntese teórica p. 102 e ss.
} 
RICCIARDI SBIZERA, José Alexandre. Direito e literatura: (des)caminhos possíveis para um ensino jurídico crítico. Revista Eletrônica Direito e Política, Programa de Pós-Graduação Stricto Sensu em Ciência Jurídica da UNIVALI, Itajaí, v.16, n.1, 10 quadrimestre de 2021. Disponível em: www.univali.br/direitoepolitica - ISSN 1980-7791

A abordagem do direito, literatura, criptomnésia e plágio tem como tema central a propriedade intelectual. O estudo ganha contornos analíticos e surgem discussões sobre fraudes e crimes contra a propriedade autoral. Neste espaço, estritamente dogmático, o direito se aproxima da literatura unicamente para regulá-la. O principal representante desta modalidade de aproximação é Richard Posner que traz problematizações sobre o plágio judicial, em que peças processuais seriam recorta e cola de modelos; que mais tarde gera recorta e cola das peças nas sentenças; que gera recorta e cola de trechos de sentenças nos acórdãos e assim por diante, criando uma verdadeira aberração sem autoria certa e em que, ao mesmo tempo, todos seriam autores. Fala também sobre a criptomnésia, ou seja, o plágio inconsciente, neste mundo em que informações e leituras apressadas em todos os veículos da mídia nos fazem verdadeiramente esquecer onde é que um ou outro escrito foi visto. ${ }^{29}$

Destes seis modos de abordagens, dois são muito úteis para os objetivos propostos no presente trabalho, ou seja, utilizar da literatura como auxilio e guia para o ensino, o aprendizado e o estudo do Direto de modo geral. Estes dois modos são: o direito na literatura; e a literatura como possibilidade de expressão do direito. A seguir, se aprofundará as considerações sobre estes meios, ilustrando-se, quando possível, com exemplos.

\section{CAMINHOS POSSÍVEIS PARA UM ENSINO JURÍDICO CRÍTICO}

Neste item serão trabalhados dois modos de abordagens que se mostram de grande utilidade para o ensino, aprendizado e estudo do Direito em sala de aula, ou mesmo fora dela. O primeiro a ser visto aqui será a literatura como possibilidade de expressão do Direito; depois, será estudado o direito na literatura. Frisa-se que não se estudará aqui as obras a fundo, sendo elas apenas citadas e contornadas com o intuito de informação e ilustração, sob pena de

${ }^{29}$ Cf. GODOY, Arnaldo Sampaio de Moraes. Direito \& literatura: ensaio de síntese teórica p. 121 e ss. 
RICCIARDI SBIZERA, José Alexandre. Direito e literatura: (des)caminhos possíveis para um ensino jurídico crítico. Revista Eletrônica Direito e Política, Programa de Pós-Graduação Stricto Sensu em Ciência Jurídica da UNIVALI, Itajaí, v.16, n.1, $1^{0}$ quadrimestre de 2021. Disponível em: www.univali.br/direitoepolitica - ISSN 1980-7791

tornar a leitura do trabalho demasiado atravancada em decorrência das citações; cabendo ao leitor buscar mais detalhes sobre os livros, se ainda não os conhece. Segue-se o primeiro modo.

A literatura como possibilidade de expressão do direito é, como foi visto, um dos meios de se estudar o Direito e Literatura. Trata-se de modo que usa de narrativas literárias intencionalmente escritas com o intuito de ensinar algo sobre o Direito e todo o universo jurídico. Normalmente quem escreve este tipo de literatura é alguém com formação acadêmica jurídica, com o objetivo claro de suscitar questionamentos, reflexões e debates entre os leitores. Possuem caráter eminentemente pedagógico, mas promovem uma leitura mais leve e agradável do que um texto ou manual técnico jurídico tradicional. É, em suma, uma ficção como outra qualquer, mas voltada a estudantes e estudiosos do Direito.

Não se pode aqui confundir estes tipos literários com dramas policiais tais como nos lembra Enrico Ferri ${ }^{30}$, como os livros de Émile Gaboriau, Victorien Sardou e Edgar Allan Poe; ou nos romances forenses ao estilo de John Grisham, Scott Turow e Richard Patterson, dentre outros, desprovidos do compromisso de ensinar, sem cunho pedagógico, sem caráter científico - para não falar, no caso dos três últimos, da duvidosa qualidade literária.

Exemplo clássico da literatura como possibilidade de expressão do Direito é, portanto, O Caso dos Exploradores de Cavernas ${ }^{31}$, que todo acadêmico de Direito provavelmente leu quando começou o curso de Direito. O livro suscita debate rico e acalorado; promove encontro entre positivismo jurídico, direito natural, realismo jurídico; exige tomada de postura e, de certa forma, demonstra previamente a linha de raciocínio jurídico que o leitor provavelmente seguirá em sua carreira profissional. Outro livro que segue nesta mesma esteira é O Caso dos Denunciantes Invejosos, de Dimitri Dimoulis ${ }^{32}$.

${ }^{30}$ FERRI, Enrico. Os criminosos na arte e na literatura. Porto Alegre: Ricardo Lenz, 2001. p, 89 e sS.

31 FULLER, Lon L. 0 caso dos exploradores de cavernas. São Paulo: Universitária de Direito, 2003.

${ }^{32}$ Cf. DIMOULIS, Dimitri. $\mathbf{O}$ caso dos denunciantes invejosos: introdução prática às relações entre direito, moral e justiça. 4. ed. São Paulo: Revista dos Tribunais, 2007. 
RICCIARDI SBIZERA, José Alexandre. Direito e literatura: (des)caminhos possíveis para um ensino jurídico crítico. Revista Eletrônica Direito e Política, Programa de Pós-Graduação Stricto Sensu em Ciência Jurídica da UNIVALI, Itajaí, v.16, n.1, $1^{0}$ quadrimestre de 2021. Disponível em: www.univali.br/direitoepolitica - ISSN 1980-7791

De outro modo, ainda que não tenha como principal objetivo o ensino, há textos de memórias em que estratégias processuais e judiciais podem ser aprendidas. Tal é o caso, por exemplo, dos Discursos de Defesa ${ }^{33}$ e dos Discursos de Acusação ${ }^{34}$, do italiano Enrico Ferri; ou das Reminiscências de um Rábula Criminalista ${ }^{35}$, de Antônio Evaristo de Morais; ou mesmo dos vários livros de narrativas, do advogado Paulo José da Costa Jr ${ }^{36}$.

Já a segunda abordagem possível e útil para os objetivos propostos no presente trabalho, ou seja, ensinar o direito é o estudo do direito na literatura. O que se faz, então, é procurar na literatura considerações, críticas ou qualquer manifestação sobre o direito. Aqui a literatura, encontrando terreno fértil e chocante para o jurista leitor de primeira viagem se torna campo para identificação e problematização das mazelas jurídicas e sociais ${ }^{37}$, apresentandose como um rico manancial de fontes para a reflexão crítica do direito ${ }^{38}$.

Isto porque as obras de ficção abordam realidades e criticam instituições; captura-se a realidade e exprime-se, sem rodeios, o que realmente se pensa; com o disfarce da prosa ficcional. ${ }^{39}$ Exemplo disso é o livro "O Cemitério dos Vivos" em que Afonso Henriques de Lima Barreto transforma em ficção as anotações feitas sobre diversos aspectos da condição a que foi colocado, lembrando e denunciando maus tratos, enquanto esteve internado pela segunda vez no Hospital Nacional de Alienados, no Rio de Janeiro. ${ }^{40}$

Outra questão que importa da literatura quando se trata de estudá-la junto ao campo jurídico é o aprofundamento do conteúdo ético do jurista. Trata-se de aprender algo com a literatura que reflete, indubitavelmente, na atuação

\footnotetext{
33 Cf. FERRI, Enrico. Discurso de defesa: defesas penais. Leme: LG, 2002.

34 Cf. FERRI, Enrico. Discurso de acusação: ao lado das vítimas. Leme: LG, 2002.

35 Cf. MORAES, Antônio Evaristo de. Reminiscências de um rábula criminalista. Rio de Janeiro: Briguet, 1989.

36 Cf. COSTA JUNIOR, Paulo José da. Crônicas de um criminalista. V. I e II. São Paulo: Jurídica Brasileira, 1999-2001.

37 Cf. GODOY, Arnaldo Sampaio de Moraes. Direito \& literatura: ensaio de síntese teórica p. 10.

38 Cf. TRINDADE; GUBERT. In. TRINDADE; GUBERT; COPETTI NETO, Direito \& literatura: reflexões teóricas. p. 50.

39 Cf. GODOY, Arnaldo Sampaio de Moraes. Direito \& literatura: ensaio de síntese teórica. p. 1011.

${ }^{40}$ BARRETO, Afonso Henriques de Lima. O cemitério dos vivos: memórias. São Paulo: Planeta do Brasil; Rio de Janeiro: Fundação Biblioteca Nacional. 2004.
} 
RICCIARDI SBIZERA, José Alexandre. Direito e literatura: (des)caminhos possíveis para um ensino jurídico crítico. Revista Eletrônica Direito e Política, Programa de Pós-Graduação Stricto Sensu em Ciência Jurídica da UNIVALI, Itajaí, v.16, n.1, 10 quadrimestre de 2021. Disponível em: www.univali.br/direitoepolitica - ISSN 1980-7791

jurídica, na formação de um pensamento ético e, em última instância, no repensamento do Direito. A literatura, segundo Antoine Compagnon, detém um poder moral ${ }^{41}$. Isto se dá em razão da reflexão que gera no leitor as afirmações e críticas de valores sociais, a partir da natureza axiológica que traz o escritor no ato da confecção da obra literária; bem como da empatia do leitor em relação aos acontecimentos narrativos e aos personagens, humanos ou não. ${ }^{42}$

Esta empatia, ou seja, a capacidade de alguém sentir o que sentiria caso se estivesse na situação ou circunstância experimentado por outra pessoa, leva o leitor a se colocar na história, a pensar a história contada tal como lhe aparece, e que, o leva a uma infinidade de possibilidades que antes poderiam não the surgir na mente, de modo que, na atuação prática, pode este leitor realizar o que experimentou e aprendeu em âmbito da ficção. Em outras palavras, ler literatura é aprender alternativas de atuações que antes, sem ela, não se imaginaria. É assim que "o universo de um livro nos surge como um mundo aberto"43. Desta forma, voltado ao Direito, a literatura proporciona o aumento da capacidade de imaginação criativa que pode fazer criar soluções frente a problemas que o Direito sozinho não foi capaz de solucionar.

Além destes já apresentados, inúmeros são os pontos a favor do estudo do direito na literatura. Neste sentido pode-se dizer que é forma de aproximar o jurista da realidade, ainda que esta aproximação seja feita através da ficção; de chamar a atenção dos juristas para o enfrentamento de problemas descobertos através da ficção e que, na realidade, já o esperavam.

Tem também a capacidade de criar, formar, manter e ampliar no leitor e, portanto, no jurista, um pensamento crítico-sensível. Provoca a autoconsciência do sujeito; expõe as múltiplas mecânicas do antidiálogo; sendo que a literatura é instrumento privilegiado de desalienação, sensibilização e humanização ${ }^{44}$.

${ }^{41}$ COMPAGNON, Antoine. Literatura para quê? Belo Horizonte: UFMG, 2009. p. 30.

42 Cf. TRINDADE; GUBERT. In. TRINDADE; GUBERT; COPETTI NETO, Direito \& literatura: reflexões teóricas. p. 54.

${ }^{43}$ ECO, Umberto. Sobre algumas funções da literatura. In. ECO, Umberto. Sobre a literatura. 2. ed. Rio de Janeiro: Record, 2003. p. 12.

${ }^{44}$ Cf. CANDIDO, Antonio. O direito à literatura. Coimbra: Angelus Novus, 2003. p. 17. 
RICCIARDI SBIZERA, José Alexandre. Direito e literatura: (des)caminhos possíveis para um ensino jurídico crítico. Revista Eletrônica Direito e Política, Programa de Pós-Graduação Stricto Sensu em Ciência Jurídica da UNIVALI, Itajaí, v.16, n.1, $1^{0}$ quadrimestre de 2021. Disponível em: www.univali.br/direitoepolitica - ISSN 1980-7791

É expandir horizontes e oxigenar a cultura; sendo que a literatura, que não se limita a produzir beleza e entretenimento, corriqueiramente toma uma postura combativa, fazendo com que o leitor se envolva num projeto de luta pela justiça social, contra as injustiças cometidas pela ordem dominante ${ }^{45}$.

Com a literatura o leitor obtém resistência e emancipação, podendo ir ao encontro dos anseios, interesses e necessidades de todos aqueles que sofrem alguma forma de opressão, exploração e exclusão ${ }^{46}$. Assim como o misticismo, as religiões, a poesia e o riso, a literatura faz-se poder nas mãos de quem não o tem.

Ler literatura é dialogar com o livro, com o autor, com os personagens, com todo o universo criado pela narrativa, e é também dialogar consigo mesmo; é aumentar e apurar, em si, a capacidade do diálogo para então dialogar com o mundo, fazendo por outro caminho o mesmo que Paulo Freire nos propõe em sua Pedagogia do Oprimido. Neste sentido se poderia, talvez, traçar um paralelo filosófico entre a dialética do senhor e do escravo de Hegel ${ }^{47}$ e a adaptação feita por Paulo Freire para ilustrar a relação opressor-oprimido ${ }^{48}$ para constatar o mesmo em relação ao leitor-literatura, leitor-livro; o que, por ora, não se arrisca.

Para ilustrar, então, pode-se citar o que se aprender de direito com a literatura nas seguintes obras: a legitimidade do direito, na Antígona de Sófocles; a relação entre vingança e justiça, na Oréstia de Ésquilo; interpretação jurídica e contratos, com O Mercador de Veneza, de Shakespeare; a complexidade psicológica da culpa, com Crime e Castigo, de Dostoievski; as incoerências das formas do sistema jurídico, com O Processo, de Franz Kafka; o absurdo do desprezo da lei para com o sujeito, em O Estrangeiro, de Albert Camus; a loucura e o tratamento jurídico e extra jurídico a ela oferecido, em O Alienista, de Machado de Assis; em O Cemitério dos Vivos, de Lima Barreto e no Canto dos Malditos, de Austregésilo Carrano Bueno; um mundo sem direitos, em Ensaio

\footnotetext{
45 Cf. LYRA, Pedro. O real no poético: Rio de Janeiro: Cátedra; Brasília: INL, 1980. p. 24.

46 Cf. COMPAGNON, Antoine. Literatura para quê?. p. 33-34.

47 Cf. HEGEL, Georg Wilhelm Friedreich. Fenomenologia do espírito. 5. ed. Petrópolis: Vozes; Bragança Paulista: Universitária São Francisco, 2008. p. 142-151.

48 Cf. FREIRE, Paulo. Pedagogia da autonomia. Passim.
} 
RICCIARDI SBIZERA, José Alexandre. Direito e literatura: (des)caminhos possíveis para um ensino jurídico crítico. Revista Eletrônica Direito e Política, Programa de Pós-Graduação Stricto Sensu em Ciência Jurídica da UNIVALI, Itajaí, v.16, n.1, 10 quadrimestre de 2021. Disponível em: www.univali.br/direitoepolitica - ISSN 1980-7791

Sobre a Cegueira, de José Saramago; humanismo jurídico-penal, em Os Miseráveis, de Victor Hugo; etc.

Assim, pode a literatura ser usada em sala de aula ou fora dela para estudos paralelos ao estudo tradicional do direito, ou como um mote sobre determinada matéria ou disciplina, como uma visão não jurídica do jurídico, uma visão além, um olhar terceiro, de um personagem, de uma situação, de um escritor literato ou de uma sociedade na qual este estava inserido em determinada época; podendo suscitar reflexões e questionamentos de problemas jurídico-sociais pretéritos que por motivo ou outro teimam em se perpetuar em nosso tempo.

Um alerta, entretanto, se faz necessário. E este alerta não é sobre mero detalhe. E que pode fazer tudo dar certo ou tudo dar errado. Aqui apresenta-se um meio de se estudar o Direito, que é com base não só mas também na literatura; propõe-se o uso da literatura como instrumental privilegiado para o estudo do Direito. Mas, e aqui fica o alerta, o pequeno detalhe que pode fazer acontecer ou não: há o humano.

Nenhuma letra, nenhuma palavra, nenhuma frase, nenhum capítulo, nenhum livro, nenhum escritor, nenhuma escola literária pode fazer absolutamente nada por nós, alunos e professores, se nós não quisermos. É por isso que se trata de um instrumental. Sozinho não opera nada. É preciso de humanos dotados de vontade de usá-los, que saiba operá-los, para que se alcance o desejado. E este humano só poderá conseguir isto lendo, para além do direito, a literatura.

\section{CONSIDERAÇÕES FINAIS}

Direito e Literatura são campos divergentes do interesse humano. Entretanto, diante de suas diferenças, demonstra-se salutar sua aproximação. Foram visto quais são as possíveis abordagens entre eles e dentre elas quais são as que melhor preenchem os objetivos do presente trabalho, qual seja, auxiliar e guiar o ensino e a aprendizagem do direito. 
RICCIARDI SBIZERA, José Alexandre. Direito e literatura: (des)caminhos possíveis para um ensino jurídico crítico. Revista Eletrônica Direito e Política, Programa de Pós-Graduação Stricto Sensu em Ciência Jurídica da UNIVALI, Itajaí, v.16, n.1, 10 quadrimestre de 2021. Disponível em: www.univali.br/direitoepolitica - ISSN 1980-7791

Para isso, então, viu-se que os melhores modos de aproximação são: a literatura como possibilidade de expressão do direito; e o direito na literatura.

O primeiro, nos casos em que a literatura é escrita e usada como veículo do direito, tendo um caráter eminentemente pedagógico tanto para o acadêmico de Direito quanto para o jurista.

E o segundo, que busca os mais diversos aspectos jurídicos nas obras literárias como forma de gerar questionamentos plurais que, por sua vez, geram a busca de respostas possíveis que antes não eram pensadas nem imaginadas em razão, justamente, da falta destes questionamentos que a literatura pode proporcionar.

Conclui-se, então, que a literatura possui caráter pedagógico privilegiado, sendo altamente instrutiva, oferecendo ao leitor esclarecimentos e explicações que a realidade e o direito sozinhos não têm paciência para dar.

No entanto, alertou-se para o problema que persiste no mundo e na academia, podendo minar todo e qualquer intento de melhora do que está posto no atual ensino jurídico: o humano que não lê, o aluno que não lê, o jurista que não lê.

\section{REFERÊNCIAS DAS FONTES CITADAS}

ADORNO, Sérgio. Os aprendizes do poder: o bacharelismo liberal na política brasileira. Rio de Janeiro: Paz e Terra, 1988.

AGUIAR, Roberto A. R. de. Habilidades: ensino jurídico e contemporaneidade. Rio de Janeiro: DP\&A, 2004.

BARRETO, Afonso Henriques de Lima. O cemitério dos vivos: memórias. São Paulo: Planeta do Brasil; Rio de Janeiro: Fundação Biblioteca Nacional. 2004.

BAZZO, Vera Lúcia. Algumas reflexões sobre a profissionalidade docente no contexto das políticas para a educação superior. In. COLAÇO, Thais Luzia. (Org.). Aprendendo a ensinar direito o direito. Florianópolis: OAB/SC, 2006. 
RICCIARDI SBIZERA, José Alexandre. Direito e literatura: (des)caminhos possíveis para um ensino jurídico crítico. Revista Eletrônica Direito e Política, Programa de Pós-Graduação Stricto Sensu em Ciência Jurídica da UNIVALI, Itajaí, v.16, n.1, 10 quadrimestre de 2021. Disponível em: www.univali.br/direitoepolitica - ISSN 1980-7791

CANDIDO, Antonio. O direito à literatura. Coimbra: Angelus Novus, 2003.

COLAÇO, Thais Luzia. Ensino do direito e capacitação docente. In. COLAÇO, Thais Luzia. (Org.). Aprendendo a ensinar direito o direito. Florianópolis: $\mathrm{OAB} / \mathrm{SC}$, 2006.

OAB/SC, 2006.

(Org.). Aprendendo a ensinar direito o direito. Florianópolis:

COMPAGNON, Antoine. Literatura para quê? Belo Horizonte: UFMG, 2009.

COSTA JUNIOR, Paulo José da. Crônicas de um criminalista. v. I e II. São Paulo: Jurídica Brasileira, 1999-2001.

CUNHA, Paulo Ferreira da. Prefácio. In. TRINDADE, André; SCHWARTZ, Germano. (Org.). Direito e literatura: o encontro entre Themis e Apolo. Curitiba: Juruá, 2008.

DEMO, Pedro. Mitologias da avaliação: de como ignorar, em vez de enfrentar problemas. 2. ed. Campinas: Autores Associados, 2002.

Pesquisa e construção do conhecimento: metodologia científica no caminho de Habermas. 7. ed. Rio de Janeiro: Tempo Brasileiro, 2009.

DIMOULIS, Dimitri. O caso dos denunciantes invejosos: introdução prática às relações entre direito, moral e justiça. 4. ed. São Paulo: Revista dos Tribunais, 2007.

ECO, Umberto. Sobre algumas funções da literatura. In. ECO, Umberto. Sobre a literatura. 2. ed. Rio de Janeiro: Record, 2003.

ECO, Umberto. Sobre a literatura. 2. ed. Rio de Janeiro: Record, 2003.

FEYERABAND, Paul. Contra o método. São Paulo: UNESP, 2007.

Adeus à razão. São Paulo: UNESP, 2010.

FERRI, Enrico. Discurso de acusação: ao lado das vítimas. Leme: LG, 2002.

. Discurso de defesa: defesas penais. Leme: LG, 2002.

Lenz, 2001.

Os criminosos na arte e na literatura. Porto Alegre: Ricardo

FONSECA, Ricardo Marcelo. Introdução teórica à história do direito. Curitiba: Juruá, 2009. 
RICCIARDI SBIZERA, José Alexandre. Direito e literatura: (des)caminhos possíveis para um ensino jurídico crítico. Revista Eletrônica Direito e Política, Programa de Pós-Graduação Stricto Sensu em Ciência Jurídica da UNIVALI, Itajaí, v.16, n.1, 10 quadrimestre de 2021. Disponível em: www.univali.br/direitoepolitica - ISSN 1980-7791

FREIRE, Paulo. Pedagogia da autonomia: sabers necessários à prática educativa. 40. ed. São Paulo: Paz e Terra, 1996.

Pedagogia do oprimido. Rio de Janeiro: Paz e Terra, 2005.

FULLER, Lon L. $\mathbf{O}$ caso dos exploradores de cavernas. São Paulo: Universitária de Direito, 2003.

GODOY, Arnaldo Sampaio de Moraes. Direito \& literatura: ensaio de síntese teórica. Porto Alegre: Livraria do Advogado, 2008.

. Direito e literatura: os pais fundadores: John Henry Wigmore, Benjamin Nathan Cardozo e Lon Fuller. In. TRINDADE, André; SCHWARTZ, Germano. (Org.). Direito e literatura: o encontro entre Themis e Apolo. Curitiba: Juruá, 2008.

. Direito e literatura: os pais fundadores: John Henry Wigmore, Benjamin Nathan Cardozo e Lon Fuller. In. GONZÁLEZ, José Calvo. (Org.). Implicación derecho literatura: contribuciones a una teoría literaria del derecho. Granada: Editorial Comares, 2008.

GONZÁLEZ, José Calvo. (Org.). Implicación derecho literatura: contribuciones a una teoría literaria del derecho. Granada: Editorial Comares, 2008.

GROSSI, Paolo. Mitologias jurídicas da modernidade. 2. ed. Florianópolis: Fundação Boiteaux, 2007.

HEGEL, Georg Wilhelm Friedreich. Fenomenologia do espírito. 5. ed. Petrópolis: Vozes; Bragança Paulista: Universitária São Francisco, 2008.

LYRA, Pedro. O real no poético: Rio de Janeiro: Cátedra; Brasília: INL, 1980.

MORAES, Antônio Evaristo de. Reminiscências de um rábula criminalista. Rio de Janeiro: Briguet, 1989.

MORIN, Edgar. A cabeça bem-feita: repensar a reforma, reformar o pensamento. 16. ed. Rio de Janeiro: Bertrand Brasil, 2009.

OST, François. Contar a lei: as fontes do imaginário jurídico. São Leopoldo: Unisinos, 2004.

REGO, Teresa Cristina. Vygotsky: uma perspective histórico-cultural da educação. 20. ed. Petrópolis: Vozes, 2009.

SBIZERA, José Alexandre Ricciardi; TRINDADE, André. Era uma vez o direito: a linguagem jurídico-artística. In. TRINDADE, André; SCHWARTZ, Germano. (Org.). Direito e literatura: o encontro entre Themis e Apolo. Curitiba: Juruá, 2008. 
RICCIARDI SBIZERA, José Alexandre. Direito e literatura: (des)caminhos possíveis para um ensino jurídico crítico. Revista Eletrônica Direito e Política, Programa de Pós-Graduação Stricto Sensu em Ciência Jurídica da UNIVALI, Itajaí, v.16, n.1, 10 quadrimestre de 2021. Disponível em: www.univali.br/direitoepolitica - ISSN 1980-7791

TRINDADE, André Karam; GUBERT, Roberta Magalhães. Direito e literatura: aproximações e perspectivas para se repensar o direito. In. TRINDADE, André Karam; GUBERT, Roberta Magalhães; COPETTI NETO, Alfredo. (Org.). Direito \& literatura: reflexões teóricas. Porto Alegre: Livraria do Advogado, 2008.

reflexões teóricas. Porto Alegre: Livraria do Advogado, 2008.

TRINDADE, André; SCHWARTZ, Germano. (Org.). Direito e literatura: o encontro entre Themis e Apolo. Curitiba: Juruá, 2008.

RECEBIDO EM: MAR/2020

APROVADO EM: AGO/2020 